\title{
Putting the safety of organic food into perspective
}

\author{
Faidon Magkos, Fotini Arvaniti and Antonis Zampelas* \\ Laboratory of Nutrition and Clinical Dietetics, Department of Nutrition and Dietetics, Harokopio University, \\ 70 El. Venizelou Avenue, 17671 Athens, Greece
}

\begin{abstract}
The demand for organic foods is constantly increasing mainly due to consumers' perception that they are healthier and safer than conventional foods. There is a need for information related to food safety to inform consumers of the health benefits and/or hazards of food products of both origins, in order to optimise the impact on health and minimise the risks. Several gaps and limitations in scientific knowledge with regard to food risk evaluation make it difficult to draw generalised conclusions. Still, some organic foods can be expected to contain fewer agrochemical residues and lower levels of nitrate than conventionally grown alternatives. On the other hand, environmental contaminants are equally present in foods of both origins. With regard to other food hazards, such as natural chemicals, microbial pathogens and mycotoxins, no clear conclusions can be drawn, although several interesting points can be highlighted. It is difficult, therefore, to weigh the risks, but what should be made clear to consumers is that 'organic' does not equal 'safe'. If producers adopt proper agricultural practices and consumers maintain hygienic conditions, risks associated with food contaminants can be minimised, regardless of the food's organic or conventional origin.
\end{abstract}

\section{Organic food: Food safety: Food hazards: Public health}

\section{Introduction}

Organic farming is a topic of marked interest in the USA (Greene, 2000) and Europe (Food and Agriculture Organization, 1999) today. Although only a small market sector until recently, it became one of the fastest growing segments of US and European agriculture during the 1990s, and is rapidly gaining ground in many other parts of the world as well (Yussefi \& Willer, 2002). Many surveys of consumer attitudes have been conducted to identify the reasons for this increased trend; among those stated, notions about food safety are fundamental for purchasing organic food (Lohr, 2001).

The past decade has been characterised by escalating public concern towards nutrition and health (Crutchfield \& Roberts, 2000) and food safety issues, such as the use of genetically modified organisms and irradiation in food production, as well as the outbreaks of bovine spongiform encephalopathy and Escherichia coli infections. All contribute to increased awareness and stimulate the interest for organically grown food (Mitchell \& Normile, 1999; Birchard, 2001). As a result, at present, consumers perceive relatively high risks associated with the consumption of conventionally grown produce compared with other public health hazards (Williams \& Hammitt, 2000, 2001).
On the contrary, there is a widespread belief that organic foods are healthier and safer than conventional foods. This perception is mainly due to the principles associated with organic food production that are difficult to dispute. The absence of synthetic chemicals and a number of other environmentally sound techniques (Soil Association, 1997) remain part of the allure of the organic movement and underlie consumer belief that organic foods are virtually free of the hazards found in conventional produce (Marcus, 2001). It is true that many supporters of organic farming rely on personal experiences and beliefs that make them more receptive to the idea that organic food is indeed superior (Morkeberg \& Porter, 2001). This perception, however, has historically led to several unsubstantiated claims, most notably the ability of organic foods to cure cancer (Jukes, 1974, 1975).

Nevertheless, scientific evidence for such claims is scarce, and the information available rarely finds its way into public discussions. In the face of such consumer expectations, it is important to carefully consider the question of safety of organic food in order to identify problems and issues that require attention. The present paper does not make a value judgement about the best approach to agricultural development; the objective is to present a critical and 
transparent overview of issues that relate to the safety of organic food. The main focus is targeted towards organic food safety and existing or potential problems associated with organic food production. An extensive referral to the well-documented food safety issues related to conventional systems is avoided.

\section{Synthetic agrochemicals}

Modern conventional agriculture uses a wide range of synthetic chemicals that inevitably leave residues in the produce. Without proper control, some pesticide residues that remain on food can create potential health risks (Fan \& Jackson, 1989). Although hard evidence is scarce, some scientists report that certain residues in conventional food could, over many years, raise the risk of cancer and other diseases in man (Marcus, 2001). Organic production standards do not allow the use of synthetic agrochemicals (Soil Association, 1997), and carefully designed long-term experiments under controlled conditions have verified that synthetic pesticide input in organically cultivated fields can be approximately $97 \%$ lower than in conventional ones (Mader et al. 2002).

Organic foods grown and processed properly, however, are not necessarily free from pesticides and other synthetic chemicals of conventional farming (Jukes, 1977). Indeed, such produce can be contaminated due to cultivation on previously contaminated soil, percolation of chemicals through soil, especially on sloping fields, unauthorised use of pesticides, cross-contamination with wind drift, spray drift from nearby conventional farms, groundwater, or even during transport, processing and storage (American Dietetic Association, 1990a,b). For example, recent evidence confirms that a number of organochlorine pesticide residues are present in the soil environment and tomato tissues from organic farming, although such pesticides have never been applied on the farm (Gonzalez et al. 2003). Wind dispersion, surface runoff and volatilisation and subsequent redeposition by precipitation of pesticides applied in the surrounding areas have been suggested to contribute to pollution of 'non-target' areas such as organic farms (Gonzalez et al. 2003). In additon, while regulations demand that farms should be free from use of prohibited substances for a time period of 2 or 3 years in order to be certified suitable for organic farming, the Organic Trade Association argues that the soil of some land is so contaminated from previous use that even after 3 years it may not be appropriate for organic production (Fisher, 1999).

Pesticide residues and/or other contaminants can occasionally be found in certified organic food. Presence, however, does not necessarily preclude the food from being labelled organic, providing all requirements related to the production process have been fulfilled (Greene, 2001). Several studies that verify the presence of synthetic agrochemicals in organic foods can be found in the literature; in most cases, pesticide residues were lower in organic than in conventional produce, although no difference could be identified in some studies (Lecerf, 1995; Woese et al. 1997; Bourn \& Prescott, 2002). While more recent data support a clear trend towards lower levels (Kumpulainen, 2001; Baker et al. 2002) and less frequent presence (Baker et al.
2002) of residues in both vegetables and fruit produced organically (Fig. 1), this conclusion cannot be generalised for other organic foods, whether cereal, potatoes, milk or meat, due to the limited number of studies and shortcomings in test design and evaluation. Regardless of these trends, and despite the fact that concerns about pesticide residues in food have resulted in extensive toxicological testing from very early on (Duggan et al. 1966), the potential long-term risks of dietary pesticides to man remain unresolved. At low levels of human exposure, however, and despite the lack of a single methodological approach that would allow for health risk assessment of low-dose chemical mixtures, it has been suggested that no real cause for concern exists (Carpy et al. 2000).

\section{Environmental pollutants}

Chemical contaminants resulting from general environmental pollution can occasionally be found in both organic and conventional food products. These compounds are also potent and may pose serious health risks (Table 1). This should be expected since persistent pollutants in the soil such as chlorinated hydrocarbons, polychlorinated biphenyls and certain heavy metals cannot be avoided through organic farming practices. Therefore, the presence or absence and the relative amount of these toxic agents in food, organic or not, will depend mainly on farm location. Areas of high contamination may occur due to industrial activity (for example, chemical manufacturing, mining and smelting operations), agricultural practices, energy production, and disposal of hazardous toxic wastes (Food and Agriculture Organization/World Health Organization, 2001b). In agreement with this assumption, most studies indicate similar levels of these pollutants in a variety of both organic and conventional foods (Lecerf, 1995; Woese et al. 1997; Kumpulainen, 2001; Worthington, 2001). Similarities are to be expected in the future, as well, given the opportunities for uptake into both types of agricultural produce.

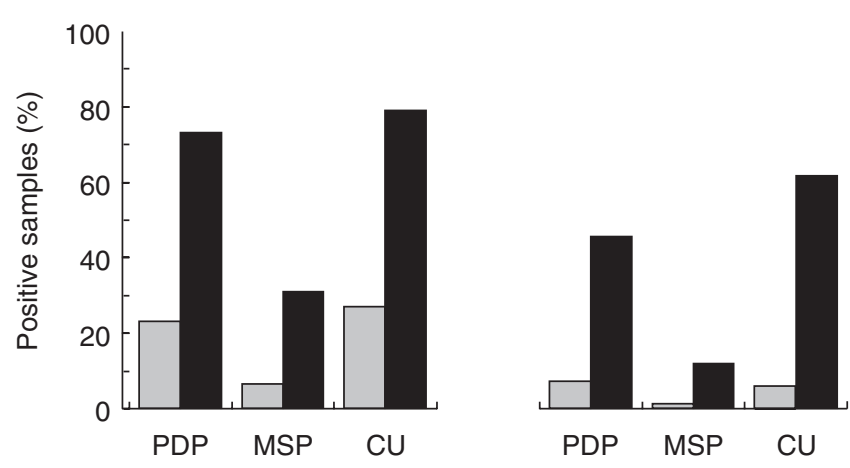

Fig. 1. Frequency of detection of at least one type (left panel) or two types (right panel) of pesticide residues in organic $(\square)$ and conventional ( $\mathbf{\square}$ ) fruits and vegetables. Data on pesticide residues in organically grown foods and foods with no market claim (assumed to be conventionally grown) were obtained from three independent US sources: the Pesticide Data Program of the US Department of Agriculture (PDP), the Marketplace Surveillance Program of the California Department of Pesticide Regulation (MSP), and private tests conducted by the Consumers Union (CU). The collected data represent tests of over 94000 food samples (derived from Baker et al. 2002). 
Table 1. Some environmental pollutants that may occasionally be found in foods*

\begin{tabular}{ll}
\hline Contaminant & Adverse effect \\
\hline $\mathrm{As}$ & Carcinogenesis \\
$\mathrm{Cd}$ & Carcinogenesis \\
$\mathrm{Cu}$ & Osteoporosis \\
$\mathrm{Dioxins}$ & Toxicity, poisoning \\
$\mathrm{Pb}$ & Carcinogenesis \\
& Hypertension \\
$\mathrm{Hg}$ & Kidney failure \\
$\mathrm{Polychlorinated}$ biphenyls & Reproductive disturbances \\
& Neurotoxicity \\
Radioactive nuclides & Other cancers \\
$\mathrm{Zn}$ & Neurotoxicity \\
& Carcinogenesis \\
\hline
\end{tabular}

* Most of these pollutants are highly carcinogenic in laboratory animals; however, the predicted adverse effects on human health due to diet-related exposure have not yet been substantiated.

Food contamination with $\mathrm{Cd}$, a known carcinogen, is widely debated and controversial. The main sources of $\mathrm{Cd}$ in soils are phosphate fertilisers, particulates from atmospheric pollution, sewage sludge, and farmyard manure (Linden et al. 2001). Use of phosphate fertilisers has declined in organic farming, which may result in lower $\mathrm{Cd}$ levels in the long term. Still, organic farmers are permitted to use crude phosphate rock containing variable amounts of $\mathrm{Cd}$, while inorganic phosphate fertilisers are cleaned of most $\mathrm{Cd}$ before application on conventional crops (Witter, 1996; Kirchmann \& Thorvaldsson, 2000). The use of sewage sludge in conventional agriculture creates further concern about possible contamination by $\mathrm{Cd}$ of conventionally grown crops and especially vegetables. Surprisingly though, soil chemical analysis often cannot fully account for the Cd added with sludge (Jones et al. 1987). Moreover, trace-element accumulation, particularly of $\mathrm{Cd}$, has been reported to be higher in the soil of organic farmland (Moolenaar, 1999), while pig manure from organic production was shown to contain higher levels of $\mathrm{Cd}$ than that from conventional production (Linden et al. 2001). Increased metal levels in soils, however, do not necessarily result in increased metal contents in the plants grown in the fields (Moolenaar \& Lexmond, 1999), and thus in foods produced by these plants. Indeed, although comparative analyses of organic and conventional foods are limited, the few studies published to date show no consistent difference in Cd levels (Lecerf, 1995; Woese et al. 1997; Jorhem \& Slanina, 2000; Worthington, 2001; Malmauret et al. 2002). Nevertheless, some preliminary data point towards higher $\mathrm{Cd}$ concentrations in conventional foodstuffs compared with organic ones (Karavoltsos et al. 2002).

Another issue of attention is the use of Bordeaux mixture (an aqueous solution of copper sulfate) and other $\mathrm{Cu}$ salts as fungicides in organic agriculture. It has been suggested that organic growers apply more frequent treatments with $\mathrm{Cu}$-based fungicides on their crops than conventional farmers do (Trewavas, 2001). Despite the fact that their use was banned after 2002, $\mathrm{Cu}$ salts remain persistent in soil and thus raise concern over food contamination with $\mathrm{Cu}$. Relevant in this respect, in reviewing a limited number of studies regarding the micronutrient content of organic and conventional foods, it was concluded that organic fruits, vegetables and grains contain on average approximately 10 $\%$ more $\mathrm{Cu}$ than conventional ones (Worthington, 2001). However, only the percentage difference was considered and no actual contents were provided. Therefore, whether this finding implies a beneficial or hazardous effect on human health remains at present unclear, especially since dietary requirements and upper tolerable levels of $\mathrm{Cu}$ intake are still subject to conjecture (Buttriss \& Hughes, 2000).

\section{Nitrate}

Nitrate is the main form of $\mathrm{N}$ supplied to crops from soil, and its content in food is an issue of some concern. A highly publicised side effect from nitrate contamination is infant methamoglobinaemia (Avery, 2001). Nitrate, per se, has not been shown to produce a carcinogenic effect in animals, but can be converted into nitrite and finally into nitrosamines by bacteria in human saliva and in the intestine (Havender, 1993). Whether or not dietary nitrate indeed constitutes a threat to human health, however, and at what level of consumption, is a matter of continuous and rigorous debate (Vallance, 1997; McKnight et al. 1999; Vermeer \& van Maanen, 2001). For instance, there is no hard evidence of a significant association between nitrate intake and gastric cancer risk in man (Van Loon et al. 1998), while consumption of vegetables is highly protective and independent of their estimated nitrate content (Pobel et al. 1995).

Regardless of the above-mentioned uncertainties, several studies have addressed the question of nitrate content in organically and conventionally grown foods. Evidence confirms a significant difference in some types of produce; organically cultivated nitrophillic vegetables (i.e. those with a high nitrate-accumulating potential), such as leaf, root and tuber vegetables, have a lower nitrate content than the conventionally grown ones, while a trend towards the same difference can also be identified in the case of potatoes (Bourn, 1994; Lecerf, 1995; Woese et al. 1997; Worthington, 1998; Bourn \& Prescott, 2002). It has been estimated that organic vegetables are approximately three times more likely to contain a lesser amount of nitrates than conventional crops and, on average, their nitrate levels are approximately $15 \%$ lower (Worthington, 2001). In contrast, organic milk has been shown to contain more nitrates than conventional milk (Woese et al. 1997). Available data with regard to other crops, such as fruit, seed and bulb vegetables, which have a low nitrate-accumulating potential, do not indicate any difference. Still, there remains a high level of uncertainty regarding the aforementioned conclusions, taking into account the large number of factors that are irrelevant to the farming system and may affect the nitrate content of crops (Table 2).

\section{Animal feeds and veterinary drugs}

Contaminants in animal feeds, such as pesticide residues, agricultural and industrial chemicals, heavy metals and radioactive nuclides, can give rise to safety hazards in foods of animal origin. Organic livestock are fed on organically produced feedstuffs; thus the potential for contamination with pesticide residues and other agricultural chemicals is reduced compared with conventional farming 
Table 2. Factors affecting the nitrate content of foods*

\begin{tabular}{|c|c|c|}
\hline Study variables & Production method & Farm location \\
\hline Duration & Cultivar & Geographical location \\
\hline Replication & Soil type & $\begin{array}{l}\text { Climate (sunlight, temperature, } \\
\text { rainfall, moisture) }\end{array}$ \\
\hline Statistical design & Organic matter & Seasonal variations \\
\hline Sampling of plant & Planting date & Storage conditions \\
\hline Sample size & Harvest date & Post-harvest processing \\
\hline \multirow[t]{2}{*}{ Nutritional analyses } & Trace elements & Plant disease \\
\hline & Nitrates in irrigation water & Nitrates in groundwater \\
\hline
\end{tabular}

* Derived from Bourn, 1994; Crutchfield \& Cooper, 1997.

methods. On the other hand, several synthetic but highly unstable chemicals are currently available to guarantee safe feed for conventional livestock. Still, neither organic nor conventional farm management can reduce the levels of persistent environmental pollutants; these may be found equally in feedstuffs and, hence, in the endproducts of animal origin of both farming systems. An educative example is a recent incident of large-scale contamination of organic meat products in Germany, due to improper storage of animal feedstuff (Tuffs, 2002). This demonstrates the considerable influence that several other aspects of the production chain may have on food safety, beyond the production system, per se.

With regard to veterinary drugs (for example, antibiotics, growth hormones), animal management in organic farms precludes the use of chemically synthesised allopathic medicines, although vaccines are conditionally permitted (Food and Agriculture Organization/World Health Organization, 2001a). Animal health in organic systems should be maintained and promoted mainly through preventive measures, such as the appropriate selection of breeds and strains, a balanced high-quality diet, and a favourable environment (Food and Agriculture Organization/World Health Organization, 2001a). These practices, however, demand precise knowledge, extensive experience and constant inspection in order to meet the desired conditions. In other words, demands on management are greater in organic than in conventional systems (Gade, 2002). Hence, it can be argued that the avoidance of animal disease in organic farms and the safety of food originating from these animals are much more dependent on individual farmers than in conventional systems. In addition, refraining from vaccines and antibiotics gives rise to concerns about animal disease outbreaks and zoonoses, should other contributing factors be present. Indeed, there are documented incidences of contamination with various pathogens in organic fish (Ogbondeminu \& Okaeme, 1986) and poultry (Engvall, 2001).

With regard to animal health in organic and conventional dairy farms, comparative studies show no fundamental differences between the two production methods (Sundrum, 2001). When animals in organic farms become sick or injured, they are treated by giving preference to phytotherapeutic or homeopathic medicinal products. The therapeutic use of synthetic allopathic medicines is not prohibited, but their use is restricted to the minimum possible (Food and Agriculture Organization/World Health Organization, 2001a). Nevertheless, the efficiency of homeopathic and phytotherapeutic medicinal products for animal treatment is mostly undocumented and under debate (Loken, 2001), thus giving cause for concern regarding increased use of synthetic medicines. In general, however, the use of synthetic veterinary drugs and growth promoters is more extensive in conventional livestock farming. As a result, the levels of such chemicals in organic foods of animal origin are expected to be lower, although comparative research in this area is absent. In addition, it should be noted that fear that livestock drug residues may remain in final food products and cause human illness is probably unsubstantiated (Mathews et al. 2001). The major concern associated with the administration of low levels of antimicrobial drugs to food-producing animals is the potential development of multidrug-resistant micro-organisms (Hamer \& Gill, 2002), an issue that has repeatedly raised doubts over the continuation of their use (Gorbach, 2001).

\section{Natural toxins}

Plants have endogenous defence mechanisms that result in toxin production, which in turn serves to protect them against predators. There is a wide range of such natural toxins, but only a few have been tested in high-dose animal cancer tests. Of those tested, almost half have shown carcinogenic action in rodents (Ames \& Gold, 1990). Moreover, it has been estimated that nearly all pesticide residues (carcinogenic or not) in diet are of natural origin (99.99 v. $0.01 \%$ synthetic); thus the daily average consumption of natural pesticides exceeds that of synthetic by almost 10000 times (Ames et al. 1990a). Decision-making bodies and legislative authorities, however, seem to be concerned about the health risks associated with synthetic chemicals only, regardless of their proportional contribution to the total human exposure, and regulate on the basis of such concerns (Silkworth \& Brown, 1996). Consequently, the assertion that natural pesticides do not jeopardise human health is presumably a fallacy, especially when taking into consideration that natural chemicals are equally as potent carcinogens as their synthetic counterparts (Ames et al. 1990b).

Comparative studies have not been conducted, however, to investigate the relative presence of such chemicals in organic and conventional foods. The above point notwithstanding, indirect evidence can lead to interesting implications. When plants are stressed from infection and/or predation, they characteristically respond with a rapid increase in defensive chemicals, and synthetic pesticides are used to reduce plant stress (Mattsson, 2000). Consequently, it can be argued that natural toxin production is suppressed in the presence of synthetic chemicals, while induced in their absence, in order to maintain defensive integrity. 
Moreover, the mechanical damage caused by insects, birds, reptiles and rodents leads to a significant increase in secondary metabolites that act as precursors of natural toxins (Harborne, 1990). It is obvious, however, that elimination of synthetic agrochemicals in arable fields leads to increased populations of insects and other biota (MacKerron et al. 1999). Indeed, increased populations of insects, arthropods, earthworms and birds have been reported on organic farms (Chamberlain et al. 1999; Soil Association, 2000; Mader et al. 2002). Although clearly beneficial for the environment and the biodiversity of the ecosystem, they may also serve as an additional source of stress to plants and, hence, are additional causes for toxin production. Another fundamental practice of organic agriculture is the use of resistant crop varieties in order to minimise damage and avoid disease. Resistance, however, is mediated by primary plant attributes, especially improved physical structure, and defence-related products, such as secondary chemicals and natural toxins (Agrawal, 2000). Thus, the selection of pest-resistant varieties in organic farming could also mean that these varieties have higher levels of natural toxins, or toxins of greater potency. In contrast, it may be assumed that conventional agriculture leads to a shift of the plant's energy use towards growth and higher yield, rather than the production of natural chemicals.

These lines of reasoning seem to support the hypothesis that organic crops have higher levels of natural toxins. Nevertheless, in the absence of comparative data, one can only speculate. Additionally, it should not be forgotten that knowledge of the specific naturally occurring chemicals that are involved in cancer causation, the mechanisms by which they act, which types of cancer they affect and the magnitude of these effects, is inadequate (Committee on Comparative Toxicity of Naturally Occurring Carcinogens, 1996). On the other hand, it is certainly true that some plant defence-related secondary metabolites may instead be beneficial to human health (Brandt \& Molgaard, 2001). Information regarding such non-nutrient food components with potential protective health effects (polyphenols, flavonoids, phyto-oestrogens, and glucosinolates) could provide some further insight into the safety of the produce but, unfortunately, it is disappointing to note the almost complete lack of comparative studies between organic and conventional food products in this area of research (Williams, 2002). It is, therefore, difficult to evaluate the significance of their presence in the diet, irrespective of the potential differences between organic and conventional crops. Nevertheless, a recent report prepared for the Soil Association of the UK concluded that certain organic crops appear to be higher in phytonutrients (lycopene in tomatoes, polyphenols in potatoes, flavonols in apples and resveratrol in red wine) (Heaton, 2001). While some organically cultivated vegetables (Welsh onion, Chinese cabbage, carrot, green pepper and Japanese radish) demonstrated significantly higher antimutagenic activity than the respective conventional crops (Ren et al. 2001)

\section{Organic pesticides}

Little attention has been paid to various other organic farming treatments. While organic proponents claim that synthetic pesticides are dangerous, it has been reported that nearly twenty different chemicals are used to maintain the safety of processed organic food (Trewavas, 2001). Nevertheless, it is asserted that organic pesticides are unstable, biodegradable, environmentally friendly, and that their external application on crops is a safe practice. Most such chemicals, however, have not received proper biological investigation in terms of their impact on human health (Dewhurst, 2001), although some may carry previously unrecognised risks (Table 3 ). The use of these chemicals by the organic community for many years indicates the power of 'assertion' rather than scientific knowledge. Unfortunately, biological pesticides have not been tested in respect of their influence on food safety and the risks, if any, remain unknown.

\section{Microbiological hazards}

Although both publicity and research have focused on preharvest food safety in animal foods, fresh produce has been implicated in major food-borne illness outbreaks (Keene, 1999). An increasing number of these cases have been directly linked to faecal contamination of fresh or minimally processed foods. Manure may contribute several

Table 3. The health risks of some organic pesticides

\begin{tabular}{ll}
\hline Properties and/or adverse effects & \multicolumn{1}{c}{ Reference } \\
\hline Rotenone (insecticide) & MacKenzie (1993) \\
Causes death in fish & Bashan et al. (1993) \\
Inhibits the electron transport chain & Isenberg \& Klaunig (2000) \\
Induces hepatocyte apoptosis & Betarbet et al. (2000) \\
Induces Parkinson's disease & \\
Bacillus thuringiensis spores (insecticide) & Smith \& Barry (1998) \\
Long-term environmental persistence & MacKenzie (1999) \\
Cause lung inflammation, internal bleeding and death in laboratory mice & MacKenzie (1999) \\
Infect wounds and damage human cells in culture & Tayabali \& Seligy (2000) \\
Produce Bacillus cereus-like cytolytic toxins & \\
Natural pyrethrins (insecticide) & Dorman \& Beasley (1991) \\
Some are as neurotoxic as synthetic pyrethroids & Nakamura et al. (1993) \\
Residues of both types have been detected in foods & Trewavas (2001) \\
They are less effective than pyrethroids and have to be used at higher doses & \\
Sodium fluoride (pesticide) & \\
Accumulates in soil, plants, wildlife, and human consumers, and may be toxic for & Connett \& Connett (2001) \\
sensitive human populations & \\
\hline
\end{tabular}


disease agents to soil, and while some die off in time, others persist for long periods (Pell, 1997). Use of untreated manure on produce crops carries a higher risk of contamination as compared with treated manure, which has markedly reduced levels of pathogens (Pell, 1997). Nevertheless, composted manure is not free of microbes, since new emerging pathogens with changing epidemiological characteristics are difficult to control (Tauxe, 1997). Contamination with faecal pathogens poses a potential threat for food-borne illness if sufficient levels of viable pathogens are contained in the produce.

Use of manure rather than chemical fertilisers contributes to an increased risk of food contamination (Beuchat \& Ryu, 1997). Utilisation of treated and untreated manure, however, as a source of crop fertiliser is common in both organic and conventional agriculture; hence potential risks apply equally. Nevertheless, 'conventional' farmers have a variety of effective synthetic fertilisers at their disposal, along with manure, while 'organic' farmers do not. Thus, it is generally accepted that the importance of manure as an alternative source of plant nutrients is greater in organic production than in conventional systems (Albihn, 2001). Additionally, the increased population of several species on organic farms (Chamberlain et al. 1999; Soil Association, 2000; Mader et al. 2002) may serve as additional contamination sources, since contact with reptiles, rodents, insects and birds may offer other portals through which pathogens can access produce (Beuchat \& Ryu, 1997).

Decontamination of food by means such as irradiation, antimicrobial agents, chemical washes and other synthetic disinfectants is prohibited in organic production, while more widely accepted practices, for instance, pasteurisation and use of chlorinated water, are only optional. Adoption of organic practices varies widely among growers (Magleby, 1998) and it cannot be ruled out that some do not practice proper disinfection techniques. Taking all this indirect information into consideration, it may be hypothesised that organic food carries a relatively higher risk of microbial contamination than conventional food, due to the increased presence of pathogens via manure and plant predators, in addition to fewer decontamination alternatives. Although this does not seem to be the case so far, as discussed later (p. 216), these considerations clearly stress the importance of potential safety drawbacks and problems encountered in organic food production, which should be pursued with both better management and more extensive microbiological testing.

Still, limited data show no significant differences in the bacterial status of organically and conventionally grown food (Marx et al. 1994; Hamilton-Miller \& Shah, 2001; Moreira et al. 2003). Nevertheless, food-borne disease outbreaks and contamination incidents have indeed been associated with organic foods, or foods produced in the organic fashion (Table 4). It is unknown, however, whether organic farming practices, per se, are to blame since contamination of produce can occur in the field or orchard during harvesting, post-harvest handling, processing, shipping, marketing or at home (Beuchat \& Ryu, 1997). In addition, caution is warranted when interpreting the results from some studies. An illustrative example is a study carried out in the UK (Gilbert \& Shepherd, 1985) that is often cited as a case of higher aflatoxin (see later; pp. 216-217) contamination in organic cereal crops. The contaminated samples, however, stocked by health-food shops in the UK, were not labelled organic (Bourn \& Prescott, 2002).

\section{Mycotoxins}

The presence of fungi gives cause for another serious concern regarding food safety. Mycotoxins are toxic by-products of certain moulds. There are several subgroups of mycotoxins, of which the major one is aflatoxins. The most toxic and carcinogenic member of this family, aflatoxin $\mathrm{B}_{1}$, is acutely poisonous, highly mutagenic and intensely carcinogenic in rodents and other animals (Havender, 1993). In man, aflatoxin $B_{1}$ can induce liver cancer at very low doses if ingested over a prolonged period of time. Aflatoxin $M_{1}$ is the major animal metabolite of aflatoxin $B_{1}$. Other mould toxins sometimes found in specific foods include fumonisins, sterigmatocystin, deoxynivalenol, ochratoxin A, T-2 toxin, patulin, penicillic acid and griseofulvin (Havender, 1993). All have shown carcinogenic activity in animal tests.

Since synthetic fungicides are not allowed in organic production, the assertion that organic crops may be more susceptible to fungi contamination seems to be based on logical, yet unproven, grounds. Interestingly, there is a negative correlation between $\mathrm{N}$ availability and sugar content in many arable crops (Eppendorfer \& Eggum, 1992; Poulsen et al. 1995). Therefore, lower $\mathrm{N}$ application in organic crops could possibly increase their sugar content, and thus make them more susceptible to fungal attack. Recent work has indeed demonstrated that organic crops may sometimes act as reservoirs for fungi and secondary sources of infection (Eltun, 1996; Zwankhuizen et al. 1998), and it has been proposed that organic farms are protected from the full effects of a disease outbreak because

Table 4. Food-borne disease outbreaks and/or contamination incidents that have been associated with organic foods or foods produced in line with organic standards

\begin{tabular}{|c|c|c|c|}
\hline Food vehicle & Pathogen & Adverse effects on health & Reference \\
\hline Raw vegetables & Not identified & Ascariasis & Oppenheim (1971) \\
\hline Raw vegetables & Escherichia coli $\mathrm{O} 157: \mathrm{H} 7$ & Gastrointestinal problems & Cieslak et al. (1993) \\
\hline Parsley in butter & Verotoxinogenic Citrobacter freundii & $\begin{array}{l}\text { Gastroenteritis, haemolytic uraemic } \\
\text { syndrome, thrombotic } \\
\text { thrombocytopenic purpura, death }\end{array}$ & Tschape et al. (1995) \\
\hline Lucerne sprouts, mesclun lettuce & E. coli O157:H7, Salmonella spp. & Not reported & Doyle $(2000)$ \\
\hline Raw vegetables & Aeromonas spp. & Not reported & McMahon \& Wilson (2001) \\
\hline
\end{tabular}


they are surrounded by conventional farms that use effective fungicides (MacKerron et al. 1999).

Given that mycotoxins constitute a major health hazard, their relative presence in foods produced organically or conventionally has been the subject of many studies. From a review of the evidence, however, it cannot be concluded that one type of farming or the other leads to an increased risk of mycotoxin contamination, even though the results vary greatly. In about half of the studies, certain types of organic produce, such as cereals, cereal-based products, fresh apples and apple cider, were found to be more susceptible to fungal contamination than the conventionally grown alternatives (Jukes, 1990; Lovejoy, 1994; Marx et al. 1995; Eltun, 1996; Malmauret et al. 2002). However, about an equal number of studies failed to confirm such a finding. Their results showed no consistent difference in either the total viable fungal content or the number of different mould species encountered, and respective toxin production did not differ (Mislivec et al. 1979; Marx et al. 1994; Jorgensen et al. 1996; Woese et al. 1997; Moreira et al. 2003). There are also documented cases of higher mycotoxin contamination in conventional food products (Schollenberger et al. 1999, 2002). The inconsistency of these data and the lack of conclusive evidence preclude drawing unequivocal conclusions. In addition, frequency and actual levels of contamination do not always coincide. For instance, a recent study has demonstrated that the rate of contamination of organic wheat samples with deoxynivalenol was approximately $40 \%$ lower than that of conventional ones, but median and maximum levels of this mycotoxin were more than 2-fold higher in organic than in conventional crops (Fig. 2) (Malmauret et al. 2002). These findings clearly illustrate that consumption patterns of specific foods have to be taken into account, as well, when attempting to evaluate consumer exposure.

\section{Conclusions and discussion}

Addressing safety issues of organic $v$. conventional food is quite complex, especially in the face of scarce and conflicting data. Therefore, overrating or generalising identified trends is neither scientifically defensible nor a prudent public health position. Such an interpretative limitation, however, is

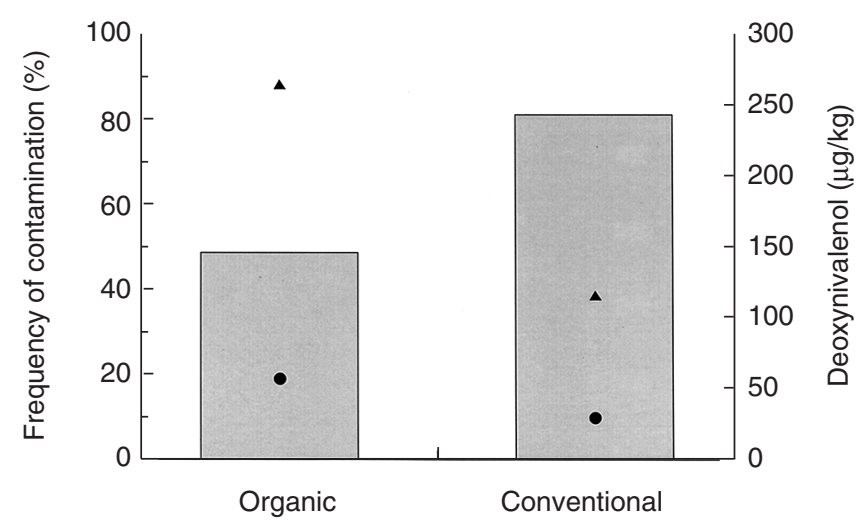

Fig. 2. Frequency of detection ( $\square$ ), and median ( $(\bullet)$ and maximum (A) levels of deoxynivalenol contamination in organic and conventional wheat (derived from Malmauret et al. 2002). not surprising or unexpected. For reasons of comparison, the reader should recall that the determination of differences in the nutritional content of crops originating from organic or conventional cultivation has been the objective of scientific research since the first quarter of the 20th century (McCarrison, 1926). Still, several reviews on the nutritional value of these crops published during the past decade have failed to reach clear or even unanimous conclusions (Bourn, 1994; Lecerf, 1995; Woese et al. 1997; Worthington, 1998, 2001; Bourn \& Prescott, 2002; Williams, 2002; Magkos et al. 2003). Taking into consideration the substantially less extensive testing of organic crops with regard to their safety characteristics, one readily realises the inadequacy of current knowledge. Despite these limitations and difficulties, however, some differences can be identified (Table 5).

Organic fruit and vegetables can be expected to contain a smaller amount of agrochemical residues than their conventional alternatives. This statement, however, cannot be applied so far to other types of produce. Furthermore, organically cultivated nitrophillic vegetables, such as leaf, root and tuber vegetables, have a lower nitrate content than the respective conventional ones; no differentiation is evident for other crops with low nitrate-accumulating potential. Organic foods of animal origin would be expected to contain lower amounts of veterinary drugs and pesticide residues than those from conventional production, although relevant research to support this assumption is lacking. Environmental contaminants, on the other hand, are equally found in food products of both origins. Regarding natural toxicants, conclusions remain tentative in the absence of comparative research. Yet, it may be hypothesised that foods produced organically have elevated levels of these compounds. There is no hard evidence to date to support the notion that organic crops are more subjected to microbial contamination than conventional ones. Finally, with regard to fungal disease and subsequent mycotoxin production, there remains a high level of uncertainty in the presence of divergent data.

Weighing the risks is therefore difficult, considering the significant gaps in scientific knowledge with regard to evaluating the presence of synthetic chemicals, nitrates, pathogenic microbes, natural toxins, environmental pollutants, and mycotoxins. In fact, no clear picture has emerged regarding the most potent food hazards, such as microbial pathogens and mycotoxins (Table 5). On the other hand, knowledge of the differences between organic and conventional produce is mainly limited to risks (synthetic toxicants, nitrate) whose importance in terms of human health is negligible and/or questionable. Therefore, in order to draw meaningful conclusions, recognised and/or potential differences between organic and conventional products have to be considered within the context of the relative impact of each food hazard on human health (Fig. 3).

In contrast to the popular perception that chemical residues in food are the major source of food contamination, recent food-borne disease outbreaks have demonstrated that microbial hazards are much more significant for food safety (Cliver, 1999). The risks due to pesticide residues and food additives are relatively minor, compared with both acute and chronic effects caused by microbiological and other naturally occurring toxicants (Fig. 3) (Cliver, 1999). In general, food-borne diseases appear to cause more illnesses 
Table 5. Comparison of organic and conventional products with respect to food hazards

\begin{tabular}{lcccc}
\hline Food hazard & Org $<$ Con & Org = Con & Org $>$ Con & Unknown \\
\hline Synthetic agrochemicals & $+^{*}$ & & \\
Environmental pollutants & $+\S$ & + & \\
Nitrate & $+\uparrow$ & & \\
Contaminants in feedstuffs & $+\uparrow$ & & \\
Veterinary drugs & & & + \\
Natural toxins & & & + \\
Organic pesticides & & & + \\
Pathogenic microbes & & + \\
Mycotoxins & & & \\
\hline
\end{tabular}

Org, organic food; Con, conventional food.

* Vegetables and fruits.

$\S$ Nitrophillic vegetables.

ๆ Foods of animal origin.

\begin{tabular}{|l|r|}
\hline Acute & Chronic \\
\hline Microbial agents \\
Phycotoxins \\
Some phytotoxins \\
Mycotoxins \\
Anthropogenic contaminants \\
Food additives \\
Pesticide residues
\end{tabular}

Fig. 3. Ranking health risks from food (modified after KuiperGoodman, 1999).

but fewer deaths than previously estimated (Mead et al. 1999). In the past decade, outbreaks of human diseases associated with the consumption of raw vegetables and fruits, or unpasteurised products originating from them, have significantly increased in number (Beuchat \& Ryu, 1997; Keene, 1999). There is no evidence, however, to indicate whether or not this increase is related to the significant increase in organic food consumption during the same period. Nonetheless, consumers' demand of minimally processed foods has had an apparent adverse influence on food safety (Zink, 1997).

During the post World War II era of synthetic agrochemicals and despite the year-on-year increase in the worldwide rate of application, there has been little overall increase of cancer incidence and mortality in the USA (Fisher \& Worth, 1995) or in Europe (Coggon \& Inskip, 1994) (exceptions being lung and AIDS-related cancers). Moreover, stomach cancer mortality has significantly decreased (Coggon \& Inskip, 1994; Fisher \& Worth, 1995), and a contributing factor to the declining incidence may have been the greater year-round availability of fresh fruits and vegetables, provided by conventional agriculture. Furthermore, there is no evidence that toxic hazards such as pesticides have had a major impact on total cancer mortality (Fisher \& Worth, 1995); populations with diets rich in fruits and vegetables have a substantially lower risk of many types of cancer (Centers for Disease Control, 1999), despite the use of synthetic agrochemicals in conventional farming. Hence, the benefits may outweigh the risks. In fact, although pesticide residues are more frequently detected (approximately three times more often; Fig. 1) in conventional than in organic food (Baker et al. 2002), actual levels in both types of produce are generally below detection limits (Kumpulainen, 2001). For example, while approximately $30 \%$ of the food consumed in the UK between 1994 and 1998 contained measurable residues, only $<1 \%$ contained violative levels (Shaw, 2000). Taking also into account that regulatory systems for agricultural chemicals are gradually becoming more stringent, it has been suggested that in the foreseeable future no meaningful difference between residue levels in organic and conventional foods will be evident (Bourn \& Prescott, 2002).

It should be emphasised, therefore, that the current food supply in the USA and Europe is much safer and healthier than in the past, and that agricultural technological achievements have greatly contributed to reduced malnutrition and improved health (Centers for Disease Control, 1999). Organic food may offer the same or even greater protection, but it is unknown whether price premiums ranging from over $40 \%$ to as high as $175 \%$ (Greene, 2001) will compromise consumption levels. A decrease in fruit and vegetable consumption due to higher prices would probably have a detrimental impact on public health status, especially since the 'five-a-day' recommendation for vegetables and fruits cannot be met by a large proportion of the population in the USA (Subar et al. 1995) or Europe (Naska et al. 2000).

In general, provided that growers adopt proper agricultural practices, both farming systems have the potential to produce safe food. Organic standards will not exempt producers and processors from compliance with general regulatory requirements such as food safety regulations, pesticide registrations and general food and nutrition labelling rules. But neither is the organic label a seal of food safety. Organic refers only to a product that has been produced in accordance with certain standards throughout the production, handling, processing and marketing stages; it does not refer to the characteristics and properties of the finished product. The asserted health benefits are impossible to quantify and do not seem, as yet, to compensate for the increased price. It is also important to note that, at present, there is no scientifically tenable evidence that any differences observed between organic and conventional food would lead to any objectively measurable effects on human health. 
Summing up, no hard evidence currently exists to support or refute claims that organic food is healthier and safer than conventional food, or vice versa, and assertions of such kind are inappropriate and not justified. They remain groundless, not only due to ethical considerations but also due to limited scientific data. The selective and partial presentation of evidence serves no useful purpose and does not promote public health. Rather, it raises fears about unsafe food. In the meantime, consumers are left in confusion and ignorance, counting the widely publicised food scares; complete fasting seems to be the only solution and 'truth' remains elusive. Still, it is logical to assume that food is healthier if not contaminated by pesticides, microbes and other toxic agents, and the possibility that some consumers draw psychological benefits from their food choices cannot be ruled out.

The main health-promoting properties of food, however, lie in their ability to provide the human organism with carbohydrates, proteins, fats, vitamins, minerals, fibre and protective factors needed for growth, repair, reproduction, energy and good health. Plants produce these complex nutrients from water, air, soil and sunlight. How well they do so is under the influence of many environmental and genetic factors, and the type of agriculture is only one variable.

\section{Acknowledgement}

The authors would like to thank Professor Louis E. Grivetti for the critical revision of the manuscript.

\section{References}

Agrawal AA (2000) Mechanisms, ecological consequences and agricultural implications of tri-trophic interactions. Current Opinion in Plant Biology 3, 329-335.

Albihn A (2001) Recycling biowaste - human and animal health problems. Acta Veterinaria Scandinavica Supplementum 95, 69-75.

American Dietetic Association (1990a) More on organic foods. Journal of the American Dietetic Association 90, 920-922.

American Dietetic Association (1990b) Organic foods: are they better? Journal of the American Dietetic Association 90, 367-370.

Ames BN \& Gold LS (1990) Chemical carcinogenesis: too many rodent carcinogens. Proceedings of the National Academy of Sciences USA 87, 7772-7776.

Ames BN, Profet M \& Gold LS (1990a) Dietary pesticides (99.99\% all natural). Proceedings of the National Academy of Sciences USA 87, 7777-7781.

Ames BN, Profet M \& Gold LS (1990b) Nature's chemicals and synthetic chemicals: comparative toxicology. Proceedings of the National Academy of Sciences USA 87, 7782-7786.

Avery AA (2001) Cause of methemoglobinemia: illness versus nitrate exposure. Environmental Health Perspectives 109, A12-A14

Baker BP, Benbrook CM, Groth E III \& Lutz Benbrook K (2002) Pesticide residues in conventional, integrated pest management (IPM)-grown and organic foods: insights from three US data sets. Food Additives and Contaminants 19, 427-446.

Bashan N, Burdett E, Guma A, Sargeant R, Tumiati L, Liu Z \& Klip A (1993) Mechanisms of adaptation of glucose transporters to changes in the oxidative chain of muscle and fat cells. American Journal of Physiology 264, C430-C440.

Betarbet R, Sherer TB, MacKenzie G, Garcia-Osuna M, Panov AV \& Greenamyre JT (2000) Chronic systemic pesticide expo- sure reproduces features of Parkinson's disease. Nature Neuroscience 3, 1301-1306.

Beuchat LR \& Ryu JH (1997) Produce handling and processing practices. Emerging Infectious Diseases 3, 459-465.

Birchurd K (2001) Europe tackles consumers fears over food safety. Lancet 357, 1276 .

Bourn D \& Prescott J (2002) A comparison of the nutritional value, sensory qualities, and food safety of organically and conventionally produced foods. Critical Reviews in Food Science and Nutrition 42, 1-34.

Bourn DM (1994) The nutritional value of organically and conventionally grown food - is there a difference? Proceedings of the Nutrition Society of New Zealand 19, 51-57.

Brandt K \& Molgaard JP (2001) Organic agriculture: does it enhance or reduce the nutritional value of plant foods? Journal of the Science of Food and Agriculture 81, 924-931.

Buttriss J \& Hughes J (2000) An update on copper: contribution of MAFF-funded research. Nutrition Bulletin 25, 271-280.

Carpy, SA, Kobel W \& Doe J (2000) Health risk of low-dose pesticides mixtures: a review of the 1985-1998 literature on combination toxicology and health risk assessment. Journal of Toxicology and Environmental Health Part B: Critical Reviews 3, 1-25.

Centers for Disease Control (1999) From the Centers for Disease Control and Prevention: Safer and healthier foods, 1900-1999. Journal of the American Medical Association 282, 1909-1912.

Chamberlain DE, Wilson JD \& Fuller RJ (1999) A comparison of bird populations on organic and conventional farm systems in southern Britain. Biological Conservation 88, 307-320.

Cieslak PR, Barrett TJ, Griffin PM, Gensheimer KF, Beckett G, Buffington J \& Smith MG (1993) Escherichia coli O157:H7 infection from a manured garden. Lancet 342, 367.

Cliver DO (editor) (1999) Eating Safely: Avoiding Foodborne Illness. New York, NY: American Council on Science and Health.

Coggon D \& Inskip H (1994) Is there an epidemic of cancer? British Medical Journal 308, 705-708.

Committee on Comparative Toxicity of Naturally Occurring Carcinogens (1996) Carcinogens and Anticarcinogens in the Human Diet: A Comparison of Naturally Occurring and Synthetic Substances. Washington, DC: National Academy Press.

Connett E \& Connett P (2001) Fluoride: the hidden poison in the National Organic Standards. Pesticides and You 21, 18-22.

Crutchfield SR \& Cooper J (1997) Valuing risk reduction: the example of nitrates in drinking water. FoodReview 20, 38-41.

Crutchfield SR \& Roberts T (2000) Food safety efforts accelerate in the 1990s. FoodReview 23, 44-49.

Dewhurst IC (2001) Toxicological assessment of biological pesticides. Toxicology Letters 120, 67-72.

Dorman DC \& Beasley VR (1991) Neurotoxicology of pyrethrin and the pyrethroid insecticides. Veterinary and Human Toxicology 33, 238-243.

Doyle MP (2000) Reducing foodborne disease: what are the priorities? Nutrition 16, 647-649

Duggan RE, Barry HC \& Johnson LY (1966) Pesticide residues in total-diet samples. Science 151, 101-104.

Eltun R (1996) The Apelsvoll cropping system experiment. III. Yield and grain quality of cereals. Norwegian Journal of Agricultural Science 10, 7-21.

Engvall A (2001) May organically farmed animals pose a risk for Campylobacter infections in humans? Acta Veterinaria Scandinavica Supplementum 95, 85-87.

Eppendorfer WH \& Eggum BO (1992) Dietary fibre, sugar, starch and amino acid content of kale, ryegrass and seed of rape and field beans as influenced by $\mathrm{S}$ - and $\mathrm{N}$-fertilization. Plant Foods for Human Nutrition 42, 359-371. 
Fan AM \& Jackson RJ (1989) Pesticides and food safety. Regulatory Toxicology and Pharmacology 9, 158-174.

Fisher AC \& Worth W (editors) (1995) Update: Is There a Cancer Epidemic in the United States? New York, NY: American Council on Science and Health.

Fisher BE (1999) Organic: What's in a name? Environmental Health Perspectives 107, A150-A153.

Food and Agriculture Organization (1999) FAO Committee on Agriculture. 15th Session: Organic Agriculture. Rome: Food and Agriculture Organization.

Food and Agriculture Organization/World Health Organization (2001a) Guidelines for the Production, Processing, Labelling and Marketing of Organically Produced Foods. Rome, Italy: Codex Alimentarius Commission and Joint FAO/WHO Food Standards Programme.

Food and Agriculture Organization/World Health Organization (2001b) The WHO Surveillance Programme for Control of Foodborne Infections and Intoxications in Europe: 7th Report on Surveillance of Foodborne Diseases in Europe 1993-1998 [C Tirado and $\mathrm{K}$ Schmidt, editors]. Berlin, Germany: FAO/WHO Collaborating Centre for Training and Research in Food Hygiene and Zoonoses.

Gade, PB (2002) Welfare of animal production in intensive and organic systems with special reference to Danish organic pig production. Meat Science 62, 353-358.

Gilbert J \& Shepherd MJ (1985) A survey of aflatoxins in peanut butters, nuts and nut confectionery products by HPLC with fluorescence detection. Food Additives and Contaminants 2, 171-183.

Gonzalez M, Miglioranza KS, Aizpun de Moreno JE \& Moreno VJ (2003) Occurrence and distribution of organochlorine pesticides (OCPs) in tomato (Lycopersicon esculentum) crops from organic production. Journal of Agricultural and Food Chemistry 51, 1353-1359.

Gorbach SL (2001) Antimicrobial use in animal feed - time to stop. New England Journal of Medicine 345, 1202-1203.

Greene C (2000) US Organic agriculture gaining ground. Agricultural Outlook 270, 9-14.

Greene C (2001) Organic labeling. In Economics of Food Labeling, pp. 26-29 [E Golan, F Kuchler, L Mitchell, C Greene and A Jessup, editors]. Washington, DC: USDA/Economic Research Service.

Hamer DH \& Gill CJ (2002) From the farm to the kitchen table: the negative impact of antimicrobial use in animals on humans. Nutrition Reviews 60, 261-264.

Hamilton-Miller JM \& Shar S (2001) Identity and antibiotic susceptibility of enterobacterial flora of salad vegetables. International Journal of Antimicrobial Agents 18, 81-83.

Harborne JB (1990) Role of secondary metabolites in chemical defence mechanisms in plants. Ciba Foundation Symposium 154, 126-134.

Havender WR (editor) (1993) Does Nature Know Best? Natural Carcinogens and Anticarcinogens in America's Food. New York, NY: American Council on Science and Health.

Heaton S (2001) Organic Farming, Food Quality and Human Health: A review of the evidence. Bristol, UK: Soil Association.

Isenberg JS \& Klaunig JE (2000) Role of the mitochondrial membrane permeability transition (MPT) in rotenone-induced apoptosis in liver cells. Toxicological Sciences 53, 340-351.

Jones KC, Symon CJ \& Johnston AE (1987) Retrospective analysis of an archived soil collection. II. Cadmium. The Science of the Total Environment 67, 75-89.

Jorgensen K, Rasmussen G \& Thorup I (1996) Ochratoxin A in Danish cereals 1986-1992 and daily intake by the Danish population. Food Additives and Contaminants 13, 95-104.

Jorhem L \& Slanina P (2000) Does organic farming reduce the content of $\mathrm{Cd}$ and certain other trace metals in plant foods? A pilot study. Journal of the Science of Food and Agriculture $\mathbf{8 0}$ 43-48.

Jukes TH (1974) The organic food myth. Journal of the American Medical Association 230, 276-277.

Jukes TH (1975) What you can tell your patients about 'organic' foods. Medical Times 103, 75-81.

Jukes TH (1979) Organic food. Critical Reviews in Food Science and Nutrition 9, 395-418.

Jukes TH (1990) Organic apple juice no antidote for alar. Journal of the American Dietetic Association 90, 371.

Karavoltsos S, Sakellari A, Dimopoulos M, Dasenakis M \& Scoullos M (2002) Cadmium content in foodstuffs from the Greek market. Food Additives and Contaminants 19, 954-962.

Keene WE (1999) Lessons from investigations of foodborne disease outbreaks. Journal of the American Medical Association 281, 1845-1847.

Kirchmann H \& Thorvaldsson G (2000) Challenging targets for future agriculture. European Journal of Agronomy 12, 145-161.

Kuiper-Goodman T (1999) Approaches to the risk analysis of mycotoxins in the food supply. Food, Nutrition and Agriculture 23, 10-16.

Kumpulainen J (2001) Organic and conventional grown foodstuffs: Nutritional and toxicological quality comparisons. Proceedings of the International Fertiliser Society 472, 1-20.

Lecerf JM (1995) Biological agriculture: interest for human nutrition? Cahiers de Nutrition et de Dietetique 30, 349-357.

Linden A, Andersson K \& Oskarsson A (2001) Cadmium in organic and conventional pig production. Archives of Environmental Contamination and Toxicology 40, 425-431.

Lohr L (2001) Factors affecting international demand and trade in organic food products. In Changing Structure of Global Food Consumption and Trade, pp.67-79 [A Regmi, editor]. Washington, DC: USDA/Economic Research Service.

Loken T (2001) Alternative therapy of animals - homeopathy and other alternative methods of therapy. Acta Veterinaria Scandinavica Supplementum 95, 47-50.

Lovejoy SB (1994) Are organic foods safer? Austin, TX: Texas Botanical Garden Society (TBGS) Newsletter. http://www.greensmiths.com/organicfoods.htm

McCarrison R (1926) The effect of manurial conditions on the nutritive and vitamin values of millet and wheat. Indian Journal of Medical Research 14, 351-378.

MacKenzie D (1993) Disease could wipe out Baltic salmon. New Scientist 140, 8 .

MacKenzie D (1999) Red flag for green spray: even organic farming is not immune to health scares. New Scientist 162, 4.

MacKerron DKL, Duncan JM, Hillman JR, Mackay GR, Robinson DJ, Trudgill DL \& Wheatley RJ (1999) Organic farming: science and belief. In Annual Report 1998/1999, pp. 60-72 [WH Macfarlane Smith and TD Heilbronn, editors]. Dundee, Scotland: Scottish Crop Research Institute.

McKnight GM, Duncan CW, Leifert C \& Golden MH (1999) Dietary nitrate in man: friend or foe? British Journal of Nutrition 81, 349-358.

McMahon MA \& Wilson IG (2001) The occurrence of enteric pathogens and Aeromonas species in organic vegetables. International Journal of Food Microbiology 70, 155-162.

Mader P, Fliessbach A, Dubois D, Gunst L, Fried P \& Niggli U (2002) Soil fertility and biodiversity in organic farming. Science 296, 1694-1697.

Magkos F, Arvaniti F \& Zampelas A (2003) Organic food: nutritious food or food for thought? A review of the evidence International Journal of Food Sciences and Nutrition 54, 537-371

Magleby R (1998) Farmers' use of 'green' practices varies widely. Agricultural Outlook 248, 22-27. 
Malmauret L, Parent-Massin D, Hardy JL \& Verger P (2002) Contaminants in organic and conventional foodstuffs in France. Food Additives and Contaminants 19, 524-532.

Marcus MB (2001) Organic foods offer peace of mind - at a price. US News and World Report 130, 48-50.

Marx H, Gedek B \& Kollarczik B (1994) Comparative studies of the bacterial and mycological status of ecologically and conventionally grown crops. European Journal of Nutrition 33, 239-243.

Marx H, Gedek B \& Kollarczik B (1995) Comparative investigations of mycotoxological status of alternatively and conventionally grown crops. European Food Research and Technology 201, 83-86.

Mathews KHJ, Buzby JC, Tollefson LR \& Dargatz DA (2001) Livestock drugs: More questions than answers? Agricultural Outlook 271, 18-21.

Mattsson JL (2000) Do pesticides reduce our total exposure to food borne toxicants? Neurotoxicology 21, 195-202.

Mead PS, Slutsker L, Dietz V, McCaig LF, Bresee JS, Shapiro C, Griffin PM \& Tauxe RV (1999) Food-related illness and death in the United States. Emerging Infectious Diseases 5, 607-625.

Mislivec PB, Bruce VR \& Andrews WH (1979) Mycological survey of selected health foods. Applied and Environmental Microbiology 37, 567-571.

Mitchell L \& Normile MA (1999) Consumer concerns elicit policy changes. In The European Union's Common Agricultural Policy: Pressures for Change, pp. 45-52 [DR Kelch, editor]. Washington, DC: USDA/Economic Research Service.

Moolenaar S (1999) The dirt on organic farming. Environmental News Network. http://www.enn.com/news/enn-stories/1999/02/ 021199/farming_1573.asp

Moolenaar SW \& Lexmond TM (1999) Heavy metal balances, Part I: General aspects of cadmium copper, zinc, and lead balance studies in agro-ecosystems. Journal of Industrial Ecology 2, 45-60,

Moreira M del R, Roura SI \& del Valle CE (2003) Quality of Swiss chard produced by conventional and organic methods. Food Science and Technology 36, 135-141.

Morkeberg A \& Porter JR (2001) Organic movement reveals a shift in the social position of science. Nature 412, 677.

Nakamura Y, Tonogai Y, Tsumura Y \& Ito Y (1993) Determination of pyrethroid residues in vegetables, fruits, grains, beans, and green tea leaves: applications to pyrethroid residue monitoring studies. Journal of AOAC International 76, 1348-1361.

Naska A, Vasdekis VG, Trichopoulou A, Friel S, Leonhauser IU, Moreiras O, Nelson M, Remaut AM, Schmitt A, Sekula W, Trygg KU \& Zajkas G (2000) Fruit and vegetable availability among ten European countries: how does it compare with the "five-aday' recommendation? DAFNE I and II projects of the European Commission. British Journal of Nutrition 84, 549-556.

Ogbondeminu FS \& Okaeme AN (1986) Bacterial flora associated with an organic manure-aquaculture system in Kainji Lake Basin area, Nigeria. International Journal of Zoonoses 13, 54-58.

Oppenheim M (1971) Rancorous consumer of 'organic' food. New England Journal of Medicine 284, 859.

Pell AN (1997) Manure and microbes: public and animal health problem? Journal of Dairy Science 80, 2673-2681.

Pobel D, Riboli E, Cornee J, Hemon B \& Guyader M (1995) Nitrosamine, nitrate and nitrite in relation to gastric cancer: a case-control study in Marseille, France. European Journal of Epidemiology 11, 67-73.

Poulsen N, Johansen AS \& Sorensen JN (1995) Influence of growth conditions on the value of crisphead lettuce. 4. Quality changes during storage. Plant Foods for Human Nutrition 47, 157-162.

Ren H, Endo H \& Hayashi T (2001) The superiority of organically cultivated vegetables to general ones regarding antimutagenic activities. Mutation Research 496, 83-88.
Schollenberger M, Suchy S, Jara HT, Drochner W \& Muller HM (1999) A survey of Fusarium toxins in cereal-based foods marketed in an area of southwest Germany. Mycopathologia 147, 49-57.

Schollenberger M, Jara HT, Suchy S, Drochner W \& Muller HM (2002) Fusarium toxins in wheat flour collected in an area in southwest Germany. International Journal of Food Microbiology 72, 85-89.

Shaw I (2002) Pesticides residues in food. Journal of Environmental Monitoring 2, 34N-37N.

Silkworth JB \& Brown JF Jr (1996) Evaluating the impact of exposure to environmental contaminants on human health. Clinical Chemistry 42, 1345-1349.

Smith RA \& Barry JW (1998) Environmental persistence of Bacillus thuringiensis spores following aerial application. Journal of Invertebrate Pathology 71, 263-267.

Soil Association (1997) Standards for Organic Food and Farming. Bristol, UK: The Soil Association Organic Marketing Co Ltd.

Soil Association (2000) The Biodiversity Benefits of Organic Farming. Bristol, UK: The Soil Association.

Subar AF, Heimendinger J, Patterson BH, Krebs-Smith SM, Pivonka E \& Kessler R (1995) Fruit and vegetable intake in the United States: the baseline survey of the Five A Day for Better Health Program. American Journal of Health Promotion 9, $352-360$

Sundrum A (2001) Organic livestock farming. A critical review. Livestock Production Science 67, 207-215.

Tauxe RV (1997) Emerging foodborne diseases: an evolving public health challenge. Emerging Infectious Diseases 3, 425-434.

Tayabali AF \& Seligy VL (2000) Human cell exposure assays of Bacillus thuringiensis commercial insecticides: production of Bacillus cereus-like cytolytic effects from outgrowth of spores. Environmental Health Perspectives 108, 919-930.

Trewavas A (2001) Urban myths of organic farming. Nature 410 , 409-410.

Tschape H, Prager R, Streckel W, Fruth A, Tietze E \& Bohme G (1995) Verotoxinogenic Citrobacter freundii associated with severe gastroenteritis and cases of haemolytic uraemic syndrome in a nursery school: green butter as the infection source. Epidemiology and Infection 114, 441-450.

Tuffs A (2002) Organic meat products contaminated with carcinogenic herbicide. British Medical Journal 324, 1416.

Vallance P (1997) Dietary nitrate: poison or panacea? Gut 40, 288.

Van Loon AJ, Botterweck AA, Goldbohm RA, Brants HA, van Klaveren JD \& van den Brandt PA (1998) Intake of nitrate and nitrite and the risk of gastric cancer: a prospective cohort study. British Journal of Cancer 78, 129-135.

Vermeer IT \& van Maanen JM (2001) Nitrate exposure and the endogenous formation of carcinogenic nitrosamines in humans. Reviews in Environmental Health 16, 105-116.

Williams CM (2002) Nutritional quality of organic food: shades of grey or shades of green? Proceedings of the Nutrition Society 61, 19-24.

Williams PR \& Hammitt JK (2000) A comparison of organic and conventional fresh produce buyers in the Boston area. Risk Analysis 20, 735-746.

Williams PR \& Hammitt JK (2001) Perceived risks of conventional and organic produce: pesticides, pathogens, and natural toxins. Risk Analysis 21, 319-330.

Witter E (1996) Towards zero accumulation of heavy metals in soils. Fertiliser Research 43, 225-233.

Woese K, Lange D, Boess C \& Bogl KW (1997) A comparison of organically and conventionally grown foods - results of a review of the relevant literature. Journal of the Science of Food and Agriculture 74, 281-293. 
Worthington V (1998) Effect of agricultural methods on nutritional quality: a comparison of organic with conventional crops. Alternative Therapies in Health and Medicine 4, 58-69.

Worthington V (2001) Nutritional quality of organic versus conventional fruits, vegetables, and grains. Journal of Alternative and Complementary Medicine 7, 161-173.

Yussefi M \& Willer H (2002) Organic Agriculture Worldwide
2002 - Statistics and Future Prospects, 4th edition. Bad Durkheim, Germany. Foundation Ecology \& Agriculture.

Zink DL (1997) The impact of consumer demands and trends on food processing. Emerging Infectious Diseases 3, 467-469.

Zwankhuizen MJ, Govers F \& Zadoks JC (1998) Development of potato late blight epidemics: Disease foci, disease gradients, and infection sources. Phytopathology 88, 754-763. 